\title{
ENERGÍA ELÉCTRICA Y PARADIGMA DE DESARROLLO: PATAGONIA SIN REPRESAS Y EMPODERAMIENTO CIUDADANO
}

\author{
Patricio Rodrigo Salinas
}




\section{PATRICIO RODRIGO SALINAS}

Ingeniero Agrónomo de la Universidad de Chile, magíster en Ciencias Ecológicas de la Pontificia Universidad Católica de Chile. Profesor adjunto del Departamento de Ciencias Ambientales y Recursos Naturales de la Facultad de Ciencias Agronómicas de la Universidad de Chile. Director ejecutivo de la Corporación Chile Ambiente. Director del Programa Medio Ambiente y Energía de la Fundación Chile 21. Secretario ejecutivo del Consejo de Defensa de la Patagonia, especialista en ordenamiento territorial, conservación de la biodiversidad, energías renovables y políticas públicas. Miembro del Directorio de la Fundación Sendero de Chile y de la Fundación BIOMAR. Coordinador del Programa Ciudadano de la Mesa Social por un Nuevo Chile. 


\title{
ENERGÍA ELÉCTRICA Y PARADIGMA DE DESARROLLO: PATAGONIA SIN REPRESAS Y EMPODERAMIENTO CIUDADANO
}

\author{
CAMBIO DE ÉPOCA: DEL INMOVILISMO DEL CONSUMIDOR AL \\ EMPODERAMIENTO CIUDADANO
}

Relevante ha sido en estos años la fuerza que han tomado las causas en defensa de la naturaleza y del medio ambiente, que motivan a nuevas generaciones, más conscientes que las anteriores, sobre los problemas de la relación de la sociedad con la naturaleza y del riesgo civilizatorio que implica seguir con los actuales modelos de desarrollo․

Nadie duda que hoy en Chile las comunidades locales, la juventud y la ciudadanía en general ejercen una mayor demanda a las instituciones de la sociedad por mejor calidad de vida y respeto a sus derechos. Fenómeno denominado por el mundo académico, político y empresarial como el proceso de aumento del empoderamiento ciudadano.

El empoderamiento es un concepto que ocupa un lugar importante en la psicología comunitaria. Esta estudia el desarrollo de comunidades que enfrentan y resuelven sus problemas, que participan y que se involucran en la toma de decisiones para transformar sus condiciones materiales y sociales. Su accionar implica un quiebre de la condición de dependencia y una estimulación de autogobierno (Krause y Jaramillo, 1998). En este marco, el empoderamiento juega un rol determinante, ya que por definición es un proceso, un conjunto de mecanismos mediante los cuales personas, organizaciones y comunidades ganan en el control de sus vidas (Rappaport, 1981).

El tópico es importante para el fortalecimiento de la democracia y el desarrollo de la ciudadanía en Chile. Su solidez va a depender en parte importante de las competencias que desarrolle la juventud -nacida poco después del comienzo de la democracia- para reflexionar sobre su realidad, acceder a recursos e influir en condiciones de vida dadas en función de metas colectivas que mejoren la calidad de vida (Flanagan y Sherrod, 1998; Flanagan y Faison, 2001).

Tanto el gobierno, el mundo político en general, las empresas eléctricas y la propia ciudadanía, no dejaron de sorprenderse del fuerte empoderamiento ciudadano -y la movilización asociada- que originó la aprobación del gobierno en la región de Aysén del proyecto HidroAysén. Iniciativa que proyecta construir cinco represas en la Patagonia y un trazado de 2.000 kilómetros a lo largo del país ${ }^{2}$ para traer la energía directamente a Santiago y a las mineras del norte del Sistema Interconectado Central (SIC) ${ }^{3}$.

En mayo del año 2011, luego de la Resolución de Calificación Ambiental (RCA) de la Comisión de Evaluación Ambiental de Aysén, más de 70.000 personas marcharon

1. http://www.chile21.cl/pdfdocs/libros/MANIFIESTO_DE_SANTIAGO.pdf

2. https://www.e-seia.cl/expediente/expedientesEvaluacion.php?modo=ficha\&id_expediente=3103211

3. http://www.elquintopoder.cl/medio-ambiente/hidroaysen-energia-para-la-mineria-o-para-el-consumo-domiciliario/ 
indignadas por la Alameda gritando como consigna "Patagonia, sin represas", denunciando el abuso de un modelo inequitativo e insustentable, y levantando con fuerza el respeto de los derechos que protegen los bienes públicos ${ }^{4}$.

Tanto para el caso del proyecto HidroAysén como para muchos otros megaproyectos, observamos cómo la actual política e institucionalidad ambiental no ha funcionado en forma adecuada y es manejada políticamente. Muchas veces, a pesar de las insuficiencias en la evaluación ambiental constatada por los servicios públicos, la autoridad política se inclina a favor de los proyectos en desmedro del ambiente y las comunidades locales o regionales. Casos como Celco en el río Cruces y Pascua Lama en Alto del Carmen, ya materializados, y Punta Alcalde en El Huasco, río Cuervo en Puerto Aysén y Castilla en Copiapó, hoy paralizados, además de otras megainversiones, demuestran que aunque no cumplían con la normativa vigente fueron aprobadas por el Ejecutivo ${ }^{5}$.

Este problema no es nuevo en la institucionalidad ambiental chilena y su doctrina se remonta a los inicios de la transición a la democracia, cuando en el gobierno del presidente Aylwin, por exigencia del mundo empresarial al entonces poderoso ministro Boeninger, no se estableció un rango ministerial para la gestión ambiental pública, sino un arreglo institucional a nivel de un servicio público de tercera jerarquía en la administración pública, argumentando que una política ambiental con más autoridad podría frenar el crecimiento económico ${ }^{6}$.

Según Juan Pablo Orrego, numerosos proyectos eléctricos se imponen y terminan teniendo graves impactos en el medio ambiente y en las comunidades, que se quedan con las externalidades negativas. Esto en contraste con el importante negocio de las empresas y el beneficio por la energía generada en el territorio impactado.

En la actualidad, según Gastó et al. (2012), vivimos un cambio de época donde observamos el surgimiento de un nuevo espíritu, que trae consigo un aumento de la conciencia de la población, un cambio cultural significativo, un fuerte respaldo ciudadano a los temas ambientales y el consecuente empoderamiento de las comunidades locales para defender sus derechos de los proyectos que les puedan afectar su sustentabilidad local ${ }^{7}$.

Se levanta hoy, desde las organizaciones ciudadanas empoderadas, un movimiento social amplio en cuyo relato o discurso aparecen con fuerza las críticas al modelo neoliberal imperante y a las instituciones públicas que no son capaces de responder a la demanda social que se ejerce en estos tiempos, en lo que ha denominado crisis de representatividad ${ }^{8}$.

Junto con las crecientes movilizaciones de 2011 y las demandas de las principales causas como educación pública de calidad y sin lucro, respeto por la naturaleza y el

4. http://www.elclarin.cl/web/index.php?option=com_content\&view=article\&rid=1391\&Itemid=11

5. http://www.indh.cl/mapa-de-conflictos-socioambientales-en-chile

6. http://www.elciudadano.cl/2011/01/28/31584/la-concertacion-debe-explicaciones-xix/

7. http://noticias.uach.cl/principal.php?pag=noticia-externo\&cod=14239

8. http://ciperchile.cl/2011/09/12/las-reveladoras-cifras-de-la-crisis-de-representatividad-de-los-parlamentarios/ 
medio ambiente, diversidad de género, trabajo decente, salud pública de calidad, entre otras, se posibilitó la articulación y coordinación de los actores sociales movilizados para potenciar dichas causas. Es así como surge la Mesa Social por un Nuevo Chile, que agrupa sobre ochenta organizaciones sociales y pone sus énfasis en un programa ciudadano que emplaza al mundo político9.

La mayoría de las organizaciones sociales, movilizadas o no, coincide con la demanda central de reformas políticas profundas a la democracia chilena, partiendo por una nueva Constitución y reglas justas, actualizadas al nuevo período que le tocará vivir al país. No se pueden resolver a cabalidad los problemas del agua, la educación, la energía, la salud, las ciudades, las regiones, entre muchos otros, si no se modifican los amarres de la actual Constitución, cuyo origen es considerado ilegítimo ${ }^{10}$.

Entre los movimientos y liderazgos que desean una nueva Constitución mediante una asamblea constituyente, es posible distinguir dos grandes corrientes de pensamiento. Por un lado, la que enfatiza la vía institucional partiendo por un plebiscito que valide legalmente la creación de una asamblea constituyente. Por el otro, la que releva las asambleas de base y locales que se organizan y movilizan esperando la crisis institucional del actual modelo para ofrecer una alternativa desde la base social. Manuel Antonio Garretón y Gabriel Salazar son los mayores representantes de ambas visiones, respectivamente.

El mundo político partidista y parlamentario no entiende mucho lo que está ocurriendo con la sociedad civil y la movilización social. No se han establecido los puentes de diálogo necesarios y han quedado desconcertados luego del alto rechazo ciudadano a su labor expresado en las encuestas ${ }^{11}$. Salvo algunos partidos con más base social, ninguno de los partidos grandes instalados en el poder tiene presencia en las movilizaciones. Es frecuente observar cómo parlamentarios son rechazados en las diversas marchas por parte de la ciudadanía ${ }^{12}$.

\section{HIDROAYSÉN Y LA CAMPAÑA "PATAGONIA SIN REPRESAS"}

La campaña "Patagonia sin Represas" nace el 2007 integrando horizontalmente, en el Consejo de Defensa de la Patagonia (CDP), el esfuerzo de varias organizaciones que ya tenían iniciativas en marcha por la protección del territorio como la Coalición Ciudadana por Aysén Reserva de Vida, coordinada por CODEFF regional, la Corporación Costa Carrera, la Corporación Privada para el Desarrollo de Aysén y la Escuela de Guías de la Patagonia, la Agrupación de Defensores del Espíritu de la Patagonia de Cochrane,

9. http://www.lemondediplomatique.cl/Cumbre-Social-por-un-nuevo-Chile.html

10. http://radio.uchile.cl/noticias/215590/

11. http://www.encuesta.udp.cl/wp-content/uploads/2013/05/PPT-Encuesta-Primer-semestre-2013-FINAdefintivopdf.pdf

12. http://www.lanacion.cl/figuras-de-la-concertacion-reciben-pifias-en-acto-cut/noticias/2010-05-01 /112628.html 
Patagonia Ríos Vivos, coordinada por Ecosistemas, Conservación Patagónica del Valle de Chacabuco y Defensa Patagonia, entre otras. Con el tiempo se integran más organizaciones al CDP hasta alcanzar alrededor de setenta entre nacionales e internacionales, principalmente de Italia, España, EEUU ${ }^{13}$. En paralelo, existen aún hoy otras que no han ingresado el CDP, pero que también realizan un trabajo importante, como la Agrupación Nacional Jóvenes Tehuelches, en todo el país. Todas ellas, junto a millones de ciudadanos, forman parte de ese espíritu que es "Patagonia sin Represas".

En el caso del CDP, la metodología seguida para desarrollar la campaña buscó organizar de manera horizontal y sin jerarquía las capacidades de las diversas organizaciones para especializar funciones o roles en lo técnico, legal, político, activismo, de comunicación, de coordinación internacional y de generación de estudios. Para así abordar la problemática de una forma integrada y no duplicar esfuerzos, cada uno con su gestión autónoma como organización, pero coordinados en la ejecución ${ }^{14}$.

Desde un comienzo, la campaña estableció una estrategia con objetivos concretos a cumplir y planes de acción anuales que evaluaban los avances y formulaban los nuevos planteamientos y acciones prioritarias. La correcta combinación en los mensajes hacia la ciudadanía de contenidos emocionales - como la belleza de la Patagonia- con contenidos racionales -como una política eléctrica sustentable que no necesita a HidroAysén o los graves impactos en el turismo regional, o los abusos del monopolio eléctrico-fueron vitales para poder llegar con dichos planteamientos a la ciudadanía ${ }^{15}$.

El objetivo definido colectivamente en el año 2007 fue el siguiente:

"Desarrollar una Campaña que actúe como nueva causa épica del país contra la Destrucción Ambiental de la Patagonia Chilena, el monopolio eléctrico y el centralismo, mediante un trabajo en los ámbitos técnico-ambiental, económico-social, político-institucional, comunicacional e internacional, cuyo fin sea lograr detener la construcción de las megarepresas y sus líneas de alta tensión en Aysén, propiciando el Desarrollo Sustentable de la Región." (CDP, 2007)

Después de cuatro años de campaña de educación y sensibilización de la población chilena sobre la importancia de conservar la Patagonia chilena como símbolo de protección ambiental, y de argumentar sólidamente en contra de los proyectos HidroAysén y Energía Austral, la población respondía gradualmente y los apoyos ciudadanos eran expresados en la encuestas de opinión ${ }^{16}$.

Luego de que la Comisión de Evaluación Ambiental de Aysén aprueba, el 9 de mayo de 2011, las represas del proyecto HidroAysén, la información se socializa rápidamente

13. http://www.patagoniasinrepresas.cl/final/quienes-somos.php

14. http://www.patagoniasinrepresas.cl/final/quienes-somos.php

15. http://www.eldinamo.cl/2010/12/28/publicistas-enjuician-campanas-de-patagonia-sin-represas-ehidroaysen/

16. http://www.cooperativa.cl/ipsos-chilenos-rechazan-instalacion-de-centrales-nucleares-e-hidroaysen/ prontus_nots/2011-04-13/123229.html 
por las redes sociales, propagando las convocatorias del CDP a marchas sucesivas de protesta en contra del gobierno en una treintena de ciudades del país ${ }^{17}$ y otras del extranjero, como Melbourne, Barcelona, Nueva York o París ${ }^{18}$. En el transcurso de ese mes, y antes de que la Corte de Apelaciones de Puerto Montt paralizara el proyecto a través de una orden de no innovar, en respuesta a los siete recursos de protección presentados por las organizaciones de "Patagonia sin Represas", a lo largo y ancho del país se habían movilizado cientos de miles de personas ${ }^{19}$. Luego, las marchas ciudadanas continuarían todo ese año por el llamado de los estudiantes a luchar por una educación pública de calidad y fin al lucro, junto con temas de la diversidad sexual y otras causas socioambientales.

En la actualidad, en Facebook, Twitter y otros soportes web, los adherentes a "Patagonia sin Represas" superan las 500.000 personas, constituyendo un importante capital político en términos de opinión ciudadana ${ }^{20}$. Un estudio reciente de la Universidad Católica dio como resultado que el 56\% de los consultados conocían y tenían algún vínculo con la campaña, siendo el más nombrado, seguido por Greenpeace con el 32\%.

El movimiento y la campaña "Patagonia sin Represas" capitaliza una larga experiencia del movimiento ambiental chileno en diversas causas, algunas ganadas, otras perdidas, desde el caso del lago Chungará, detenido por la Corte Suprema en 1985, hasta Ralco, Pascua Lama, Celco-río Cruces-Mehuín, Cascada, Trillium, Campiche, entre otras. Algunas de esas causas se perdieron y hoy las localidades pagan las consecuencias de los graves impactos ambientales. Algunas aún están en desarrollo y otras fueron definitivamente un éxito para el ambientalismo chileno, como fue la creación de un área protegida de 280.000 hectáreas en los terrenos que fueron propiedad de Trillium en Tierra del Fuego ${ }^{21}$, o el proyecto Cascada, en Puerto Montt, que frenó su fábrica de astillas de bosque nativo, luego de las acciones de campaña en defensa del bosque nativo ${ }^{22}$.

En febrero del año 2012, nuevamente la región de Aysén da una sorpresa al levantarse masivamente a través de las organizaciones sociales, exigiendo al gobierno respuestas en numerosos temas regionales pendientes y no resueltos por el gobierno central. Entre los once puntos del petitorio estaba el desarrollar un plebiscito vinculante por el tema de las represas en Aysén, tema que no tuvo ninguna respuesta por parte del Ejecutivo, como tantos otros de esa demanda regional ${ }^{23}$.

17. http://www.diarioreddigital.cl/index.php?option=com_content\&view=article\&id=3485:rechazo-ahidroaysen-las-movilizaciones-que-vienen $\&$ catid $=125$ : movimiento-social $\$$ Itemid $=98$

18. http://www.latercera.com/multimedia/galeria/2011/05/683-28876-7-chilenos-contra-hidroaysen-enel-extranjero.shtml

19. http://www.veoverde.com/2012/05/hidroaysen-colbun-retira-su-participacion-del-mega-proyectoindefinidamente/

20. http://www.eldinamo.cl/2013/06/10/vota-sin-represas-campana-insta-a-candidatos-a-rechazarrepresas-en-la-patagonia/

21. http://www.chilesustentable.net/wp-content/uploads/kalins-pdf/singles/sara-larrain-\%25e2\%2580 $\% 259$ ca-pesar-de-los-obstaculos-triunfa-la-conservacion\%25e2\%2580\%259d.pdf

22. http://www.scielo.cl/scielo.php?pid=S0719-09482012000100008\&script=sci_arttext

23. http://www.eldivisadero.cl/noticias/?task=show\&id=30563 
Con relación a casos anteriores de problemas ambientales producidos por proyectos de inversión de relevancia nacional, existe percepción en diversos analistas que la oposición de "Patagonia sin Represas" a HidroAysén ha sido una de las campañas más emblemáticas y con éxitos relativos importantes. Siguiendo la tendencia de mayo de 2011, se han levantado con mucha más fuerza que antes diversas localidades por demandas en problemas ambientales específicos que les afectan la calidad de vida y que no están dispuestas a seguir soportando. Casos como Freirina ${ }^{24}$, Pelequén ${ }^{25}$, Montenegro ${ }^{26}$, Rengo $^{27}$, Chanco ${ }^{28}$, Quellón ${ }^{29}$, entre otros, demuestran el cambio cultural que se está produciendo en el país por aspirar a tener ciudades y una vida rural más limpia de lo que ocurre en la actualidad.

Si bien el proceso de evaluación ambiental de HidroAysén sigue en trámite, no está para nada claro qué va a pasar con la iniciativa, especialmente si está condicionada a leyes de transmisión actualmente en discusión en el Parlamento, como la de Concesiones Eléctricas y de la Carretera Eléctrica Pública.

\section{UN MODELO ELÉCTRICO QUE NO SATISFACE LA DEMANDA SOCIOAMBIENTAL}

Sin entrar a cuestionar la irregular privatización de ENDESA y los orígenes de la actual política eléctrica, que es tema para un extenso artículo, se constata que el actual modelo de desarrollo eléctrico es de alto impacto socioambiental. Se trata de un sistema monopólico, concentrado y sin competencia que no ha logrado los objetivos iniciales que lo justificaron, es decir, que diera seguridad de suministro y a costos razonables. Tres empresas -ENDESA, Colbún y AES Gener- manejan sobre el 90 \% de la energía eléctrica del SIC, el principal del país ${ }^{30}$.

El monopolio eléctrico existente en Chile, mal llamado "natural", ha tenido como resultado el dominio de una política solo orientada a la gestión de la oferta, sin incorporar la gestión de la demanda. También ha omitido la mirada territorial, la diversificación de la matriz, el desarrollo de las Energías Renovables No Convencionales (ERNC), el Uso Eficiente de le Energía (UEE) y la participación de los actores locales en los proyectos ${ }^{31}$.

Hemos reducido la participación del Estado en el mercado eléctrico a una mera oficina de partes, donde las empresas informan sus proyectos de inversión para ser colocados

24. http://radio.uchile.cl/noticias/153131/

25. http://noticias.terra.cl/nacional/pelequen-suspenden-movilizaciones-hasta-el-viernes,84843ffb7c9963 10VgnVCM5000009ccceb0aRCRD.html

26. http://www.emol.com/noticias/nacional/2012/12/22/575856/montenegro-se-une-a-protestas-contraplantas-de-cerdos.html

27. http://www.rengoaldia.cl/la-comuna/2427-imovilizacion-ciudadana-en-rengo

28. http://radio.uchile.cl/noticias/148689/

29. http://www.biobiochile.cl/2013/05/30/dirigentes-de-quellon-llegan-a-acuerdo-con-manalich-tras-4dias-de-movilizacion-social.shtml

30. http://www.chilesustentable.net/2007/01/30/ENDESA-chile-colbun-y-aes-gener-controlan-el-91-delsector-electrico/

31. http://www.energiaciudadana.cl/docs/InformeCompleto.pdf 
en el plan de obras. Según Larraín y Maldonado (2011), la capacidad regulatoria es muy básica y, desde la promulgación de la Ley General de Servicios Eléctricos en 1982, se ha descartado la planificación como instrumento de política y, últimamente, incluso el lineamiento del ordenamiento territorial, establecido en la Estrategia de Desarrollo Eléctrico del gobierno, ha sido dejado de lado por las visiones neoliberales extremas que ven detrás de estos instrumentos un retorno del Estado a una planificación centralizada similar a la de los socialismos reales.

La tendencia del mercado ha sido ir tras el combustible más barato y rentable, sin visiones estratégicas, lo que quedó demostrado con la crisis del gas argentino, que comprometió seriamente la seguridad de suministro, a pesar de que era sabido con antelación el colapso en el abastecimiento de dicho recurso ${ }^{32}$.

Tenemos, actualmente, un mercado eléctrico costoso, vulnerable y concentrado que no ha sabido resolver los problemas que le exige la sociedad, ya sean de índole ambiental o social, radicada en las localidades de los proyectos, o bien económico, por la falta de competencia, el que ha sido criticado desde los nuevos empresarios que desean incorporarse a la actividad, especialmente desde los proyectos de ERNC.

Entre las principales críticas al modelo eléctrico chileno, una que siempre se deja de lado, siendo de las más limitantes, es el cambio en el modelo marginalista y el mercado spot que, manejado por un Centro de Despacho Económico de Carga (CDEC), constituye una barrera de ingreso a las ERNC y un incentivo perverso a mantener un sistema en crisis que se vea obligado a quemar petróleo y así subir el costo marginal y el precio de la energía que se despacha al mercado ${ }^{33}$.

El CDEC, esta especie de "mesa" del sistema eléctrico chileno cuyos funcionarios son pagados por las propias generadoras y que no tiene parangón en el mundo, decide quién entra y quién sale del sistema y los costos marginales del mercado spot, es decir, los precios. La ciudadanía y el sector académico no existen para el modelo y la presencia del Estado es muy débil.

Cabe señalar que la Ley General de Servicios Eléctricos de 1982 ha sido modificada por las Leyes No 19.940 (Corta I), 20.018 (Corta 2), 20.220 (Quiebras) y 20.257 (ERNC), bajo el espíritu de proteger el negocio de la energía y no a los ciudadanos. Sobre esta materia, citando al ex senador Ricardo Núñez: "Eran leyes como traje a la medida para evitar los conflictos entre las grandes empresas" (Chile 21, 2008).

Las iniciativas legales impulsadas por el actual gobierno tampoco fueron hacia una reforma integral del sistema eléctrico nacional, solo han intentado abordar los temas más limitantes del actual modelo, como lo son las concesiones eléctricas y la transmisión troncal, mal llamada Carretera Eléctrica Pública, y ha dejado de lado las reformas más demandadas por la ciudadanía y la mayoría de los parlamentarios, como el 20/20 (meta del 20\% de ERNC al año 2020), el Reglamento del net metering (o medidores inteligentes), el fomento a las ERNC y a la Eficiencia Energética, el cambio en el CDEC y el ordenamiento territorial, entre otras.

32. http://economia.terra.cl/noticias/noticia.aspx?idNoticia=200404261938_INV_27638493

33. http://www.energiaciudadana.cl/docs/capitulos/03CAP.pdf 
De las críticas más relevantes al modelo eléctrico chileno, realizadas por diversos autores, podemos enunciar que:

- No se ha garantizado la seguridad de suministro: Lo que fue uno de los objetivos centrales de la Ley General de Servicios Eléctricos de 1982, que estableció el modelo marginalista. Luego de más de treinta años de funcionamiento, el sistema posee una fragilidad importante para el suministro eficiente.

- Los precios más altos de América: Otra de las finalidades de la ley mencionada, como era operar a costos razonables, tampoco se cumplió y los precios son altos en contraste con el hecho de que las empresas del sector son las más rentables después de la minería.

- La integración vertical no está resuelta: Empresas generadoras como ENDESA y sus distribuidoras -Chilectra, entre otras- pertenecen al mismo dueño que ENERSIS, eludiendo la prohibición legal al respecto.

- Concentración de mercados eléctricos: Que tres empresas manejen sobre el 94\% de toda la generación nacional, teniendo solo el $84 \%$ de la capacidad instalada, da cuenta de que el mercado no es competitivo y actúa como monopolio natural, introduciendo barreras de ingreso a la competencia.

- Nulo desacoplamiento entre crecimiento y consumo: Todos los países OCDE han desacoplado su crecimiento económico de su consumo eléctrico, mejorando la intensidad energética a través de normativas de uso eficiente. En el caso chileno, el crecimiento del consumo eléctrico va en paralelo al crecimiento del PIB, incluso, en ocasiones, superándolo.

- Tendencias exponenciales insostenibles: Con las tasas de crecimiento en el consumo eléctrico que se proyectan, según John Wilson (2007), estaríamos alcanzando el consumo per cápita de California entre el 2018 y 2020. En la Figura 1 se muestra a Chile con relación a EEUU, en su conjunto, y al estado de California.

Figura 1

COMPARACIÓN DE TASAS DE CRECIMIENTO DEL CONSUMO ELÉCTRICO DE CHILE CON CALIFORNIA Y EL CONJUNTO DE EEUU

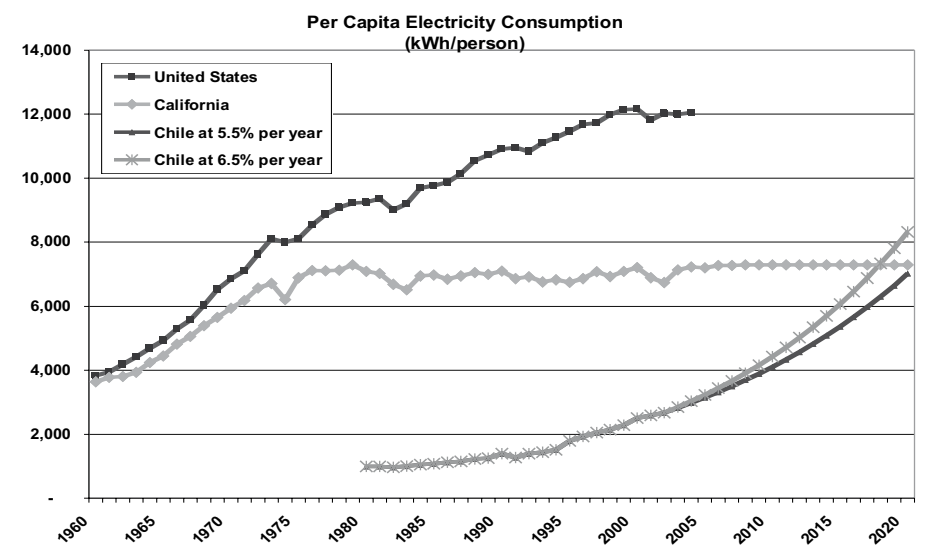


- Externalización de costos sociales y ambientales: Los daños a la propiedad privada, sea por impactos directos o por depreciación, son meras externalidades que las pagan los afectados sin compensación alguna. Los daños al paisaje, que deprecian nuestro patrimonio natural, tampoco son valorizados. Para qué decir la gravedad en los daños a la salud, que se pagan con cáncer, muertes y pérdida de calidad de vida. Hoy, el sector eléctrico pareciera estar más preocupado de la huella de carbono, que sin duda es importante, pero para nada del arsénico, el níquel, el vanadio y otros contaminantes tóxicos que se emiten a la atmósfera.

- Incipiente política de UEE y de fomento a las ERNC: El uso eficiente de la energía es aún muy incipiente en el país y se ha enfatizado en los que menos consumen, por ejemplo, cambiar ampolletas ayuda, pero el sector residencial consume alrededor del 17\% de la electricidad del SIC y menos del 10\% de la del Sistema Interconectado del Norte Grande (SING). En cambio, poco se hace para poner normas al sector minero e industrial, que son cerca del 66\% del consumo del SIC y sobre el $90 \%$ del SING. El temor al reclamo empresarial porque le suban los costos es más fuerte que la voluntad política de los gobiernos en pro de la sustentabilidad del sector.

Entre otros, los resultados de este sistema monopólico, sin competencia, no solo han puesto barreras para otros generadores, como los de ERNC, sino que están obteniendo una sobre utilidad fuera de lo común, más allá del $10 \%$ legal, que no es adecuadamente fiscalizado ${ }^{34}$.

Incluso los obispos se han sumado a las críticas al modelo económico. En la reciente Carta Pastoral, la Conferencia Episcopal señala que "el nivel de desarrollo económico alcanzado convierte a la realidad desigual en algo explosivo". Según los obispos, "una avanzada tecnología, manejada por el mercado y orientada primordialmente al crecimiento económico, puede tener efectos gravísimos para la conservación de la naturaleza que es nuestro hábitat. Esto no solo es grave en sí mismo, sino que destruye el futuro y es muy doloroso para las culturas ligadas a la tierra, como son las de los pueblos originarios de nuestro país, que consideran a la tierra como a una madre"35.

\section{LA RESPUESTA DEL GOBIERNO: IMPROVISADA E INSUFICIENTE}

Sin duda, si el presidente Piñera hubiera sabido la fuerte reacción ciudadana que tendría en su contra por la aprobación de la etapa de las represas del proyecto HidroAysén, lo habría pensado dos veces. Fue en esa fecha cuando su popularidad se desplomó desde un $60 \%$ a menos de un $30 \%$ en pocos meses. Las masivas movilizaciones rompieron el miedo, hicieron despertar al pueblo dormido, la gente salió a las calles, se empoderó produciendo

34. http://www.elmostradormercados.cl/destacados/electricas-4/

35. http://documentos.iglesia.cl/conf/doc_pdf.php?mod=documentos_sini\&id=4192 
un remezón político de proporciones ${ }^{36}$. Fenómeno que va de la mano con la pérdida de credibilidad de las instituciones políticas de la actual democracia, Congreso, gobierno, partidos políticos y parlamentarios. Algunos periodistas se refirieron a la situación vivida en el país como el "mayo chileno" en alusión al "mayo francés" de 1968 en Paris ${ }^{37}$.

En su mensaje a la Nación de 2011, el presidente Piñera incorporó en su discurso el tema eléctrico, anunciando cambios legislativos a la transmisión mediante la Carretera Eléctrica y la creación del Comité Asesor en Desarrollo Eléctrico (CADE). A pesar de no haber estado en el programa de gobierno, el tema eléctrico se instaló en la agenda política gracias a las movilizaciones de "Patagonia sin Represas" en contra de HidroAysén.

También sus ministros y voceros salieron en esa fecha a inculpar al gobierno anterior por la responsabilidad de haber admitido el proyecto HidroAysén a evaluación ambiental, eludiendo así la responsabilidad de haberlo aprobado mediante una Resolución de Calificación Ambiental (RCA). Más que responder a la ciudadanía, que se la ignoró sustantivamente, la discusión se entrampó en una comedia de culpabilidades mutuas ${ }^{38}$.

También por parte de Laurence Golborne, entonces ministro de Energía, hubo intensiones de incorporar a representantes de "Patagonia sin Represas" a la CADE, invitándolos a conversar y así intentar frenar las movilizaciones que se extendían sin parar. En dicha ocasión, los representantes invitados rechazaron integrarse a dicha comisión y se anunció la creación de un referente propio, la Comisión Ciudadana Técnico-Parlamentaria (CCTP), que con posterioridad entregaría una propuesta alternativa al gobierno y al presidente ${ }^{39}$.

Como estrategia, el gobierno, para no pagar aún mayores costos políticos, ha ido postergando cada cierto tiempo la reunión del Comité de Ministros que se debe pronunciar sobre las reclamaciones contra la RCA que aprobó HidroAysén. Además, decidió trasladar el problema al Parlamento poniendo en discusión las llamadas leyes eléctri$\mathrm{cas}^{40}$, leyes que inmediatamente fueron vistas como un traje a la medida para favorecer megaproyectos como HidroAysén y Energía Austral ${ }^{41}$.

En la discusión de estas leyes en la Comisión de Energía y Minería del Senado, hay parlamentarios que han escuchado y participado de las propuestas ciudadanas e incorporado sus posiciones para mejorar dichas normativas. También se han respaldado otros proyectos que van en la línea de favorecer un nuevo modelo eléctrico, tal como el de net metering ${ }^{42}$ y la ley de ERNC de $20 \%$ al año $2020^{43}$.

36. http://issuu.com/psegura/docs/5_hidroaysen_fin

37. http://eldesconcierto.cl/entrevista-a-patricio-rodrigo/

38. http://www.lun.com/Pages/NewsDetail.aspx?dt=16-05-2011\%200:00:00\&BodyID=0\&PaginaId=34

39. http://www.elmostrador.cl/noticias/pais/2011/05/30/constituyen-comision-ciudadana-para-matrizenergetica/?utm_source=newsletter\&utm_medium=email\&utm_campaign=titulares

40. http://www.emol.com/noticias/economia/2013/01/22/580347/longueira-ve-extraordinario-nivel-deconsenso-politico-en-proyecto-de-concesiones-electricas.html

41. http://www.elciudadano.cl/2012/10/08/58208/ojo-con-las-llamadas-leyes-hidroaysen/

42. http://www.chilesustentable.net/2012/01/18/aprueban-ley-de-generacion-residencial-net-meteringen-el-senado/

43. http://www.camara.cl/prensa/noticias_detalle.aspx?prmid=72166 
Los proyectos centrales en discusión en los que el gobierno ha manejado las urgencias son dos: el de la Carretera Eléctrica Pública y el que agiliza la entrega de concesiones eléctricas.

\section{Carretera Eléctrica Pública}

La CCTP ha alertado a la opinión pública que el proyecto de Carretera Eléctrica elaborado por el Ejecutivo no responde a las necesidades de transmisión que requiere el país, que no facilita la inyección de electricidad generada con medios del tipo ERNC a los sistemas interconectados y que tampoco beneficia a los consumidores, los que deberán pagar las holguras de futuros trazados nominados como "de interés público". En los hechos, beneficia a un pequeño grupo de grandes empresas que desarrollan proyectos de generación de alto impacto ambiental, ubicados en diversas regiones de Chile y particularmente en la Patagonia ${ }^{44}$.

El senador Antonio Horvath (2013) expresó en su momento que la Carretera Eléctrica "es una ley para HidroAysén, que faculta al Presidente de la República a imponer servidumbres eléctricas para líneas de transmisión, facilitando así el acceso a recursos disponibles para la producción de energía eléctrica en el territorio nacional" y llamó al gobierno a "responder públicamente, si el proyecto de Carretera, tal como se ha presentado, se podría utilizar para establecer el trazado de transmisión de HidroAysén" $" 45$.

Desde el mundo ambiental se criticó que esta Carretera impone franjas de "interés nacional" sobre territorios públicos y privados, sin posibilidad de apelación, amenaza las Áreas Silvestres Protegidas, los territorios indígenas, al no incluir la consulta del Convenio 169, y que pasaría por encima de las Leyes de Medio Ambiente y de Bosque Nativo ${ }^{46}$.

También, se critica que busca que las empresas eléctricas eludan decenas de permisos sectoriales que hoy permiten resguardar el interés público, que impone mayores costos a los consumidores, que pagarían el $75 \%$ del valor de la transmisión, y que no fomenta las energías limpias, al contrario, las encarece, porque el sistema troncal tiene distinto voltaje y no se definen los ramales que se asimilan como troncales. Esto último es una grave insuficiencia legislativa.

Al parecer, el gobierno, luego de la definición de su estrategia eléctrica y de dar orientaciones para la política pública, no está abordando el problema en su globalidad y continúa con un análisis en partes pequeñas e inconexas que impiden ver los cambios que refleja el discurso político.

La propuesta novedosa de este gobierno fue la de ofrecer entregar un "mapa de zonas" que identifique las áreas con alguna protección, en las que se viabilicen las posibilidades de inversión en proyectos eléctricos. Encargado al Ministerio de Bienes Nacionales luego

44. http://radio.uchile.cl/noticias/169138/

45. http://www.theclinic.cl/2012/08/30/proyecto-de-ley-de-carretera-electrica-desata-multiples-criticasen-oficialismo-y-oposicion/

46. http://www.terram.cl/index.php?option=com_content\&task=view\&id=10864 
del caso Barrancones, se ha quedado detenido por visiones contrapuestas al interior del gobierno con los que piensan que es el mercado el que debe decidir, en plena libertad, dónde instalarse con sus proyectos y el Estado no debe inmiscuirse con políticas de ordenamiento territorial.

Al parecer, estos temas pendientes harán que se dilate la discusión del proyecto de la Carretera Eléctrica Pública, y será el próximo gobierno el que deba retirarlo o continuar la discusión y resolver la crítica ciudadana sobre si lo que se necesita es una Carretera Eléctrica Pública para HidroAysén o un Sistema Nacional de Transmisión que resuelva no solo los sistemas troncales, sino los ramales, e incorpore los conceptos de generación distribuida, redes inteligentes y desarrollo de las energías renovables.

\section{Concesiones eléctricas}

El Proyecto de Ley (PL) sobre Procedimiento para otorgar concesiones eléctricas, enviado por el Ejecutivo a tramitación a la Cámara de Diputados el 3 de mayo de 2013, consiste en un artículo único que modifica y reemplaza algunas normas de la Ley General de Servicios Eléctricos, con el objeto de acelerar el procedimiento de otorgamiento de concesiones eléctricas a proponentes privados.

Para acelerar el trámite de las concesiones eléctricas, el proyecto pone gravámenes sobre los terrenos de los productores agrícolas, ganaderos, emprendimientos de turismo y conservación.

El movimiento social y ambiental, preocupado por el proyecto, se ha organizado a través del CDP y la CCTP para participar en los debates y asesorar a algunos parlamentarios que tienen mayor afinidad con las propuestas ciudadanas que las del Ejecutivo.

Tanto el CDP como la CCTP han visto en este proyecto una posibilidad de mejorar la legislación al respecto y, más que oponerse en su totalidad, han formulado un conjunto de indicaciones que, desde la mirada de la ciudadanía, hace aportes para logar una mejor ley.

Entre las recomendaciones a incorporar en las indicaciones se pueden mencionar:

- Evitar que se restrinjan las oposiciones a los propietarios de terrenos (legitimación activa).

- Incorporar, cuando corresponda, la consulta a las comunidades indígenas (OIT 169) y la consulta a las comunidades relacionadas con áreas silvestres protegidas.

- Corregir el privilegio que se le otorgó al solicitante de la concesión eléctrica por sobre los solicitantes de concesiones de otros sectores. Esto vulnera el derecho de propiedad.

- Impedir que se rompa la unicidad de los proyectos para su evaluación, debido a que permite dividir concesiones, lo cual, en el fondo, genera una presión sobre áreas sensibles, ya que al permitir que avance la concesión en áreas no sensibles, se privilegiaría el concepto de hechos consumados.

- Evitar que se restrinjan las causales de reclamación de los afectados. 
- Bloquear la entrega de autorización para ocupación material de terrenos al concesionario, si existen recursos pendientes.

- Evitar la entrega de concesiones a perpetuidad, similar a la figura utilizada en la Ley de Pesca.

Estos aportes se han visto bloqueados por un acuerdo del gobierno con algunos diputados y senadores, que desean despachar la ley lo antes posible, a pesar de no estar resueltos los problemas de fondo, acuerdo hecho una vez más sin tomar en cuenta la opinión ciudadana.

También existe un tercer proyecto, aún no despachado al Parlamento, que favorece la inversión en minería y proyectos eléctricos.

\section{Ley Proinversión}

El mundo ciudadano, representado por "Patagonia sin Represas", fue el primer actor que cuestionó la iniciativa, que aún no conocemos, excepto por las declaraciones de prensa del Ejecutivo y los empresarios. En dichas definiciones, que influirían sobre el futuro de varias regiones completas vinculadas a proyectos de energía y minería, no hubo participación de representantes de dichos territorios, siendo que esas políticas les afectarían directamente en sus vidas y actividades económicas ${ }^{47}$.

La percepción de las organizaciones sociales del país sobre dicho proyecto consiste en estimar que el futuro del país y sus regiones lo desean definir solo los grandes intereses corporativos eléctricos y mineros, quienes fijan las metas del país con el apoyo del gobierno y a espaldas de la ciudadanía. Desean resolver las trabas administrativas, indican, pero significa, en concreto, pasar por sobre las mayorías que rechazan proyectos como HidroAysén, Castilla, Energía Austral y otros, con la idea de amarrar todo antes que cambie el gobierno y lleguen otros al poder.

Desde "Patagonia sin Represas" afirman que la cumbre confirmó lo que la campaña ha venido diciendo por años y ha sido insistentemente desmentido por los voceros de HidroAysén: la nueva energía es para la gran minería. También indican que, con este proyecto, simplemente buscan acuerdos empresa-gobierno para continuar con su gran negocio, pasando por sobre los intereses ciudadanos de las comunidades y las regiones ${ }^{48}$.

Mencionan que pedir que se termine con la judicialización de los proyectos es buscar una licencia para vulnerar derechos y entrometerse en otro poder del Estado. Indican que lo que corresponde hoy y siempre es respetar el Estado de Derecho, sin aceptar presiones que socavan la institucionalidad y nos conducen hacia una crisis de gobernabilidad $^{49}$.

47. http://issuu.com/psegura/docs/insertocumbreproinversion

48. http://issuu.com/psegura/docs/insertocumbreproinversion

49. http://issuu.com/psegura/docs/insertocumbreproinversion 
La disminución de la "seguridad jurídica" de las inversiones, afirman, se debe principalmente a los errores de los últimos gobiernos por no resolver adecuadamente la institucionalidad ambiental ni las reglas del juego, dejando a un sistema extremadamente vulnerable, cuya judicialización será directamente proporcional a la pérdida de confianza ${ }^{50}$.

\section{LAS SOLUCIONES: DE LA PROTESTA A LA PROPUESTA}

El movimiento ambientalista y ecologista chileno, con una de existencia de más de cuarenta años, ya está en condiciones de pasar de la protesta socioambiental y las movilizaciones a las propuestas de desarrollo sustentable. Confluyen un marco teórico suficiente, experiencias nacionales e internacionales, una ciudadanía más consciente y la necesidad de resolver a la brevedad las graves amenazas planetarias y locales, como el cambio climático y la pérdida de biodiversidad, respectivamente.

Para el caso de la política eléctrica existen además, para el país, las fuentes renovables en abundancia, que posibilitan un crecimiento importante para las décadas siguientes, junto con haber reflexionado sobre los problemas de dicha política y las orientaciones desde la visión ciudadana. Además, los tiempos sociales y políticos que vive el país implican una necesidad de avanzar en más y mejor democracia.

\section{Bases ecológicas de un nuevo paradigma}

Desde los comienzos del ambientalismo existió una fuerte relación con la ciencia ecológica, desde donde se nutrieron las críticas a un sistema económico considerado insustentable y también de los marcos teóricos que posibilitan hacer propuestas de cambios estructurales en la lógica del interés social y colectivo, en contrapartida al interés privado y corporativo que domina en las decisiones políticas.

Entre esos elementos del marco teórico que han dado sustento a las causas ambientales en el país, y en especial a la campaña "Patagonia sin Represas", podemos mencionar algunos.

El desarrollo sustentable, que viene desde la Comisión Brundland (1985), hasta lo planteado por Nijcam (1991), Gastó (1994) y otros, donde se busca conciliar objetivos económicos con los sociales y ambientales.

La Figura 2 expone una forma de entender el problema del desarrollo sustentable.

50. http://issuu.com/psegura/docs/insertocumbreproinversion 


\section{Figura 2}

\section{RELACIÓN DE LO ECONÓMICO, LO SOCIAL Y LO AMBIENTAL}

EN EL DESARROLLO SUSTENTABLE O SOSTENIBLE

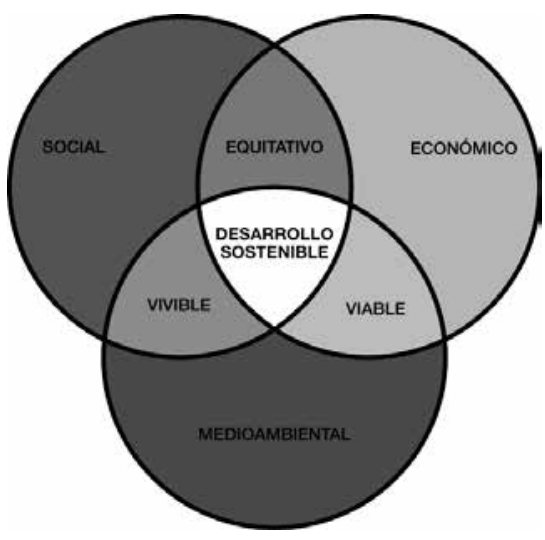

También, en la Figura 3, basada en el triángulo de Nijcam, se observa la identificación de un resultado donde se concilian y armonizan las variables económicas, sociales y ambientales.

Figura 3

CONCILIACIÓN DE OBJETIVOS ECONÓMICOS, SOCIALES Y AMBIENTALES

EN EL CONTEXTO DE LA SUSTENTABILIDAD

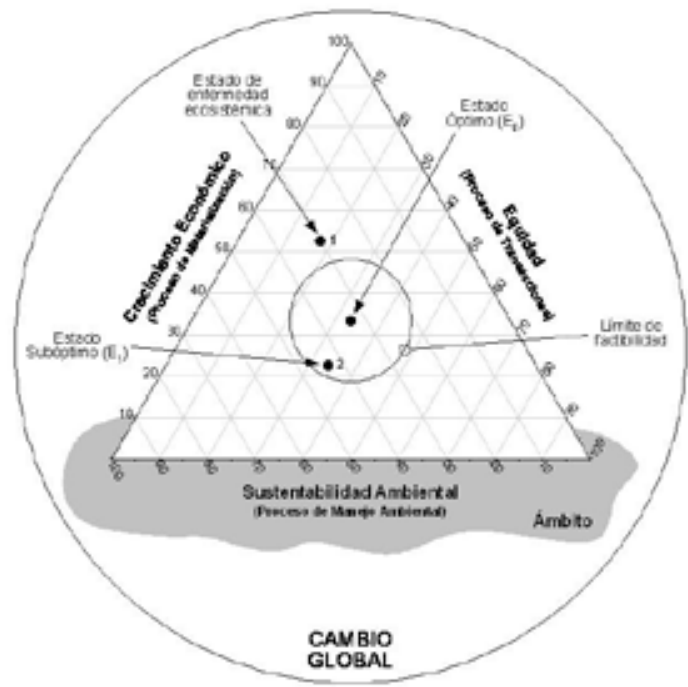

Además, las soluciones de sustentabilidad no son rígidas y únicas, se requiere contemplar la ubicación territorial de las acciones de desarrollo para que efectivamente se respeten las restricciones que la naturaleza le impone a las actividades humanas para la mantención del equilibrio ecológico, con sus ciclos biogeoquímicos, la mantención de 
la biodiversidad, los ciclos hidrológicos, entre otros factores que mantengan la estabilidad de los ecosistemas. La figura siguiente expone las soluciones de sustentabilidad, desde la mirada del ordenamiento del territorio para diferentes ámbitos.

\section{Figura 4}

SUSTENTABILIDAD Y ÁMBITOS TERRITORIALES
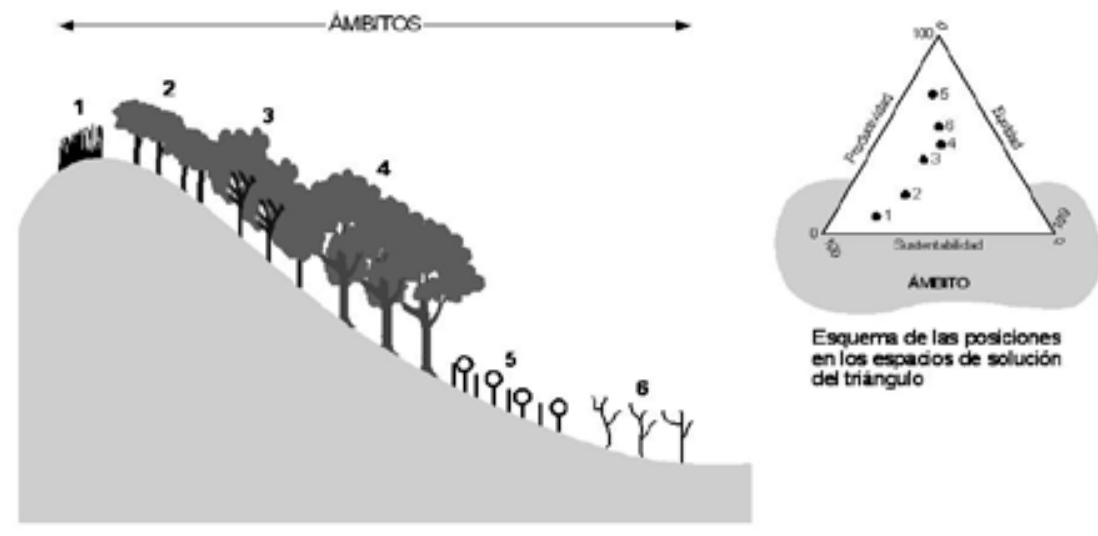

La búsqueda de este tipo de soluciones, implica una renuncia a las visiones inminentemente sectoriales, y avanzar en una mirada basada en el pensamiento complejo y la trasdisciplina que nos aproximen a un enfoque holístico de los problemas de la relación sociedad-naturaleza-tecnología. La Figura 5 expone el enfoque monístico de la relación sociedad-naturaleza.

\section{Figura 5}

ENFOQUE MONÍSTICO DE LA RELACIÓN SOCIEDAD-NATURALEZA EN FUNCIÓN DEL ORDENAMIENTO TERRITORIAL Y EL IMPACTO AMBIENTAL

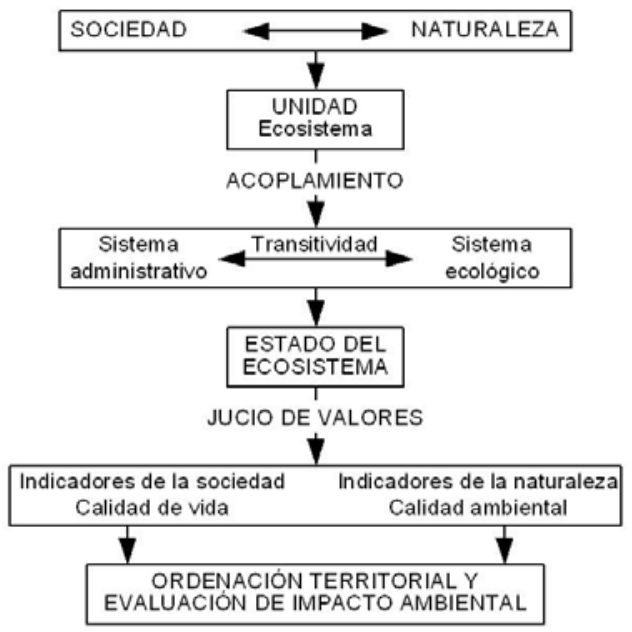


La Figura 6 expone la articulación entre diferentes niveles de organización de la naturaleza y de la sociedad, definiendo los límites o grados de libertad para la toma de decisiones que respeten los criterios de sustentabilidad del desarrollo. También, representa un enfoque metodológico de articulación de ciencias duras con ciencias blandas.

Figura 6

GRADOS DE LIBERTAD PARA LA TOMA DE DECISIONES DESDE LA SUSTENTABILIDAD

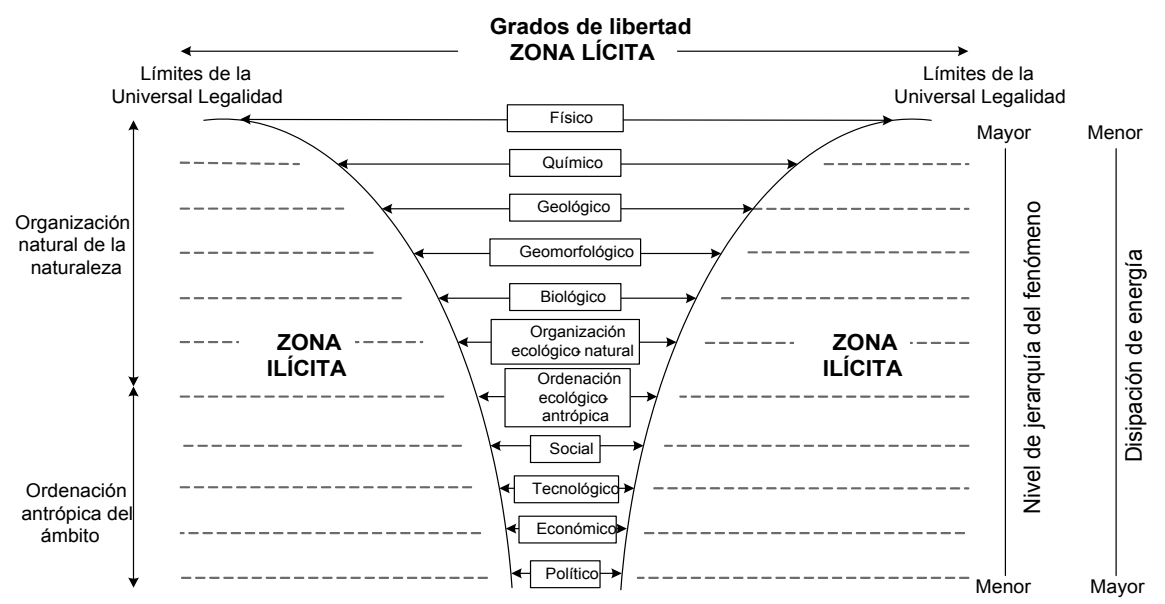

\section{El potencial de las ERNC y de la EE}

Diversos autores y expertos, entre los que se encuentran Amory Lovins ${ }^{51}$, Stephen Hall y Roberto Román ${ }^{52}$, e incluso el propio Banco Interamericano de Desarrollo ${ }^{53}$, han demostrado con datos y llegado a la conclusión de que el país es privilegiado en fuentes de ERNC.

El Cuadro 1, elaborado por la Corporación Chile Ambiente (2012), resume algunas de las conclusiones con los potenciales de energías renovables que posee el país, indicando el tipo de energía, la fuente del dato, el potencial total estimado y el potencial que sería económico en la actualidad.

51. http://www.futurorenovable.cl/2011/11/seminario-matriz-energetica-2011-dr-amory-lovins-chileposee-condiciones-para-las-ernc/

52. http://www.eldivisadero.cl/noticias/?task=show\&id $=25675$

53. http://www.eldinamo.cl/2013/06/19/estudio-del-bid-cita-a-hidroaysen-como-ejemplo-de-unproyecto-que-genera-conflictos-sociales-y-ambientales/ 


\section{Cuadro 1}

POTENCIAL TOTAL Y POTENCIAL ECONÓMICO DE LAS ENERGÍAS RENOVABLES CHILENAS

\begin{tabular}{|l|c|}
\hline \multicolumn{1}{|c|}{ Tipo de energía - Fuente } & Potencial Total - (Económico) \\
\hline Geotermia - Universidad de Chile, 2006 & $16.000 \mathrm{MW}$ - (4.000 MW) \\
\hline Centrales de paso - Acera A.G, 2006 & $33.000 \mathrm{MW}$ - (10.000 MW) \\
\hline Mareomotriz - G. Hassa, 2009, BID/CDE & $161.900 \mathrm{MW}$ - (2.000 MW) \\
\hline Solar térmica - Universidad de Chile, 2006 & $937.000 \mathrm{MW}$ - (10.000 MW) \\
\hline Solar fotovoltaica - Universidad de Chile, 2010 & $1000.000 \mathrm{MW} \mathrm{-} \mathrm{(3.000} \mathrm{MW)}$ \\
\hline Eólica - UTFSM, 2008 & $40.000 \mathrm{MW} \mathrm{-} \mathrm{(15.000} \mathrm{MW)}$ \\
\hline Biomasa - Chile Ambiente, 2009 & $1.000 \mathrm{MW} \mathrm{-} \mathrm{(600} \mathrm{MW)}$ \\
\hline
\end{tabular}

Destacan los grandes potenciales de la energía solar, tanto térmica como fotovoltaica, con cifras que superan el millón de MW instalados y la mareomotriz, sobre los 160.000 MW para las costas del país. También son rescatables los potenciales eólicos sobre los 40.000 MW y las centrales de paso que superan los 30.000 MW.

Según información del Centro de Energías Renovables (2012), los proyectos enmarcados como renovables no convencionales ascienden a ciento cuarenta, los que sumarían una capacidad de $8.749 \mathrm{MW}$, es decir, poco más de tres veces lo que contempla el proyecto HidroAysén, con una inversión necesaria de US\$22.451 millones.

El 54\% de la nueva generación sería eólica. Con las cuarenta y cinco iniciativas de este tipo en trámite, sumarían 4.684 MW y un desembolso de US\$9.664 millones. A su vez, los proyectos solares representan el 34\% de los MW totales, es decir, 3.276 MW que necesitarían una inversión de US\$ 11.066 millones para concretar las cuarenta y una centrales contempladas.

La tecnología minihidro alcanzaría 476 MW de construirse los cuarenta y cinco proyectos ingresados al SEIA, que totalizan US\$ 1.112 millones. En biomasa son ocho las iniciativas por un monto de US\$ 429 millones para alcanzar 263 MW. En geotermia hay solo un proyecto, que generaría 50 MW con una inversión de US\$ 180 millones.

Existe en el Ministerio de Energía un Plan de Acción de Eficiencia Energética Rentable, con una meta de $15 \%$ de eficiencia al año 2025, que ha tenido dificultades mayores para su implementación en el actual gobierno. Dicho plan reduciría el consumo de electricidad en unos 19.500 GWh, evitando la construcción de centrales de generación equivalentes a una capacidad de $2.600 \mathrm{MW}$.

\section{Nueva visión ciudadana de la política eléctrica}

Lo que más se reclama al gobierno, desde la mirada de los movimientos sociales que hacen seguimiento de la reforma eléctrica, es la carencia de una visión de largo plazo de la política eléctrica y de una reforma integral que apunte a dichos objetivos. La Estrategia Nacional de Desarrollo Eléctrico definida por el Ejecutivo en febrero del 2011, se ha limitado a poner urgencias a los proyectos de transmisión dejando de lado temas como la 
meta del 20\% de energías renovables al 2020, compromiso de programa que, con base al nuevo acuerdo con algunos parlamentarios, se postergaría al año 2025 la eficiencia energética, el Reglamento de net metering, el cambio en el CDEC, las barreras de entrada a las renovables, entre otras; todas necesarias para que exista mayor competencia en el mercado eléctrico.

Las propuestas ciudadanas encabezadas por el CDP y la CCTP plantean un cambio de paradigma eléctrico a través de una reforma integral del sistema eléctrico, lo que implica cambios en el marco regulatorio que, al menos, considere:

- Competencia y precios justos: No puede haber competencia en un mercado concentrado donde tres actores controlan el 94\% de toda la electricidad del país. Para ello, debe cambiarse la Ley General de Servicios Eléctricos de 1982, en específico el modelo marginalista, por otro de costo medio, poner límites al porcentaje de participación de los actores del mercado, reforzar que la electricidad antes que un negocio es un servicio público y recuperar, por parte del Estado, la planificación con una mirada estratégica y capacidad para regular el buen funcionamiento de los mercados eléctricos. También se debe incorporar, en el nuevo paradigma de la política eléctrica, una mirada desde la demanda, que genere escenarios prospectivos del consumo para cada territorio o región y, acorde con ellos, se planifique la oferta optimizando los recursos energéticos que tengan más cercanía con esa demanda. En la figura $N^{\circ} 7$ se presentan los resultados de una investigación de Bloomberg (2012), donde se demuestra que al 2020 prácticamente todas las energías renovables serán competitivas, tanto para el SIC como para el SING, dada la reducción de costos que hoy tienen las ERNC.

Figura 7

COSTOS NIVELADOS DE ERNC Y GENERACIÓN CONVENCIONAL AL 2020

(Bloomberg, 2012)

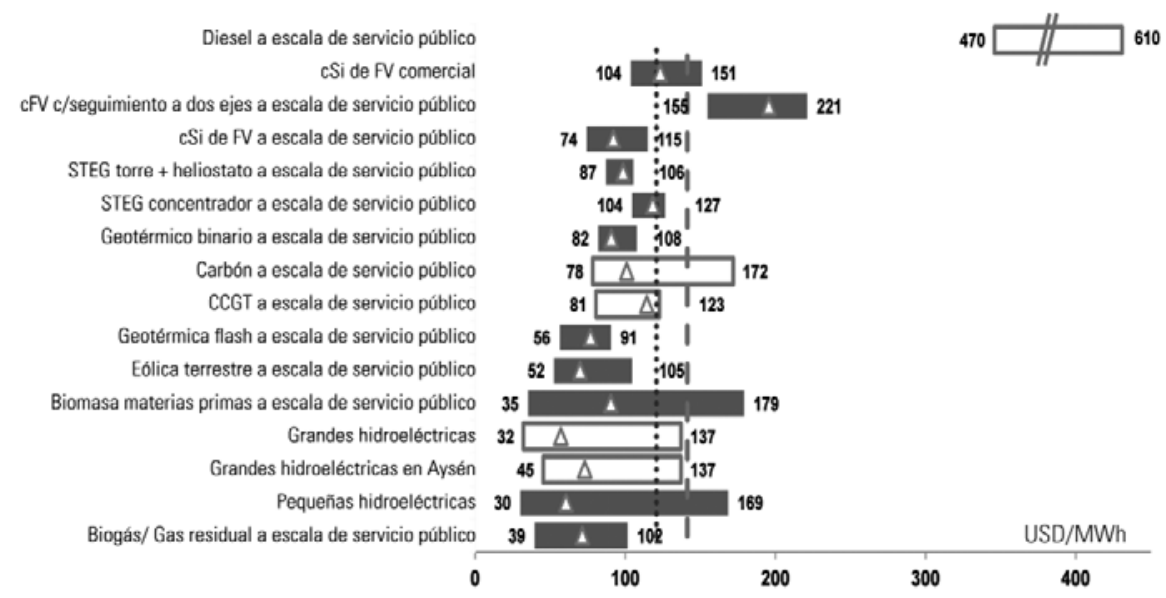

- LCOE de ERNC $\square$ LCOE convenciónal $\triangle$ Escenario central …. Precio de energía en el SIC - Precio de energía en el SING 
Este nuevo mercado, regulado adecuadamente y con competencia real, requiere de un cambio profundo en el CDEC, de manera que pase a ser un órgano donde participen todos los actores involucrados, sea transparente e independiente, y no manejado, como ocurre en la actualidad, por funcionarios cuyas remuneraciones provienen de las mismas generadoras. Se necesita un CDEC verdaderamente democrático y que garantice la confianza requerida por una nueva política eléctrica.

- Sistema Nacional de Transmisión y Generación Distribuida: Más que una carretera eléctrica para viabilizar las represas en Aysén, "Patagonia sin Represas" ha planteado un sistema nacional de transmisión y un avance con redes inteligentes interconectadas, tipo redes neuronales, que posibiliten sacar la energía desde las fuentes renovables a los centros de consumo diversificando el número de actores que participan del mercado. Un sistema que relacione adecuadamente los troncales con los ramales, en inverso al actual PL de la llamada Carretera Eléctrica, que solo mira los troncales y deja indefinido los ramales que son fundamentales en un nuevo paradigma que fortalezca la generación distribuida. La mirada territorial de la demanda induce a una política que optimiza recursos energéticos existentes con la mayor cercanía al consumo, además de bajar las distancias de transmisión, disminuyendo con ello los costos de las líneas de alta tensión, significativamente las pérdidas de energía y los impactos ambientales y en el paisaje. La Figura 8 muestra un esquema de lo que podría ser la Generación Distribuida (GD) para el SIC, que abastece al 93\% de la población del país.

\section{Figura 8}

EJEMPLO DE UNA PROPUESTA DE GD PARA EL SIC

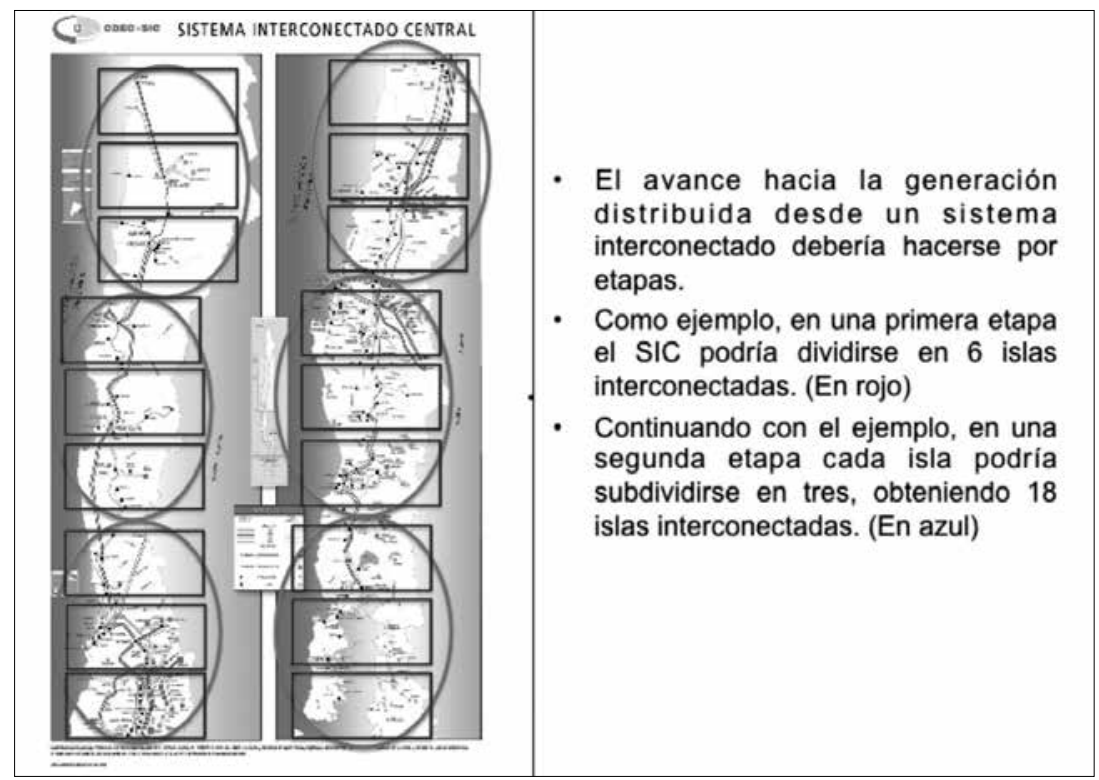


En un país tan diverso como Chile, las islas energéticas como Aysén, Magallanes y otros pueblos, cumplen una función que optimiza los recursos y deben ser fortalecidas, al menos hasta que ingresen al interconectado. La generación domiciliaria a través del net metering (medidores inteligentes), puede aportar una energía no menor al sistema, y hoy son opciones reales dadas las nuevas tecnologías disponibles, la legislación vigente y, especialmente, los costos del sistema fotovoltaico, que han bajado significativamente. En esto último, dada la aprobación de la ley respectiva, solo falta un buen reglamento que incentive su implementación masiva.

- Sustentabilidad ambiental: Hoy día, por el significativo aumento de la conciencia ambiental de la población, ya no es posible implantar proyectos energéticos que atenten contra el medio ambiente en los territorios. Si bien la institucionalidad ambiental vigente no es mucho lo que puede hacer, dado el ordenamiento jurídico y voluntad política al respeto, la carencia de reglas claras hace que la judicialización de los proyectos sea una espada de Damocles para cualquier iniciativa privada de megaenergía. Las mayores movilizaciones ciudadanas que se han producido en estos años se están originando en causas ambientales y por la protección de los bienes comunes, que es parte del cambio cultural de la sociedad chilena, lo que requerirá un ajuste institucional y de las empresas privadas. Ya no es posible que los objetivos de política de energía eléctrica se contrapongan con los objetivos de protección ambiental, los desafíos de protección de la biodiversidad, de evitar el cambio climático y de proteger la ruralidad en su integralidad; requieren armonizar y compatibilizar el desarrollo eléctrico con la conservación de la naturaleza y el ambiente.

- UEE: Hoy se las considera una fuente más en la matriz eléctrica, el uso eficiente de la energía es aún muy incipiente en el país y se ha enfatizado en los sectores que menos consumen, por ejemplo, cambiar a ampolletas eficientes ayuda, pero el sector residencial consume alrededor del 19\% de la electricidad del SIC y menos del 10\% del SING. En cambio, poco se ha hecho para poner normas al sector minero e industrial, que representan más del 66\% del consumo del SIC y sobre el 90\% del SING. El propio Plan de Eficiencia Energética que hizo el gobierno y que no lo ha puesto en marcha, estima que, con una meta de $15 \%$ de eficiencia al año 2025, se reduciría el consumo de electricidad en unos 19.500 GWh, evitando la construcción de centrales de generación equivalentes a una capacidad de $2.600 \mathrm{MW}$.

- ERNC y Empleo: Reconociendo el potencial del país presentado en el Cuadro 1 , donde las fuentes de energías renovables están en todo el territorio, una política al respecto viene a iniciar una transición de reemplazo del paradigma de las grandes concentraciones en grandes plantas, para desde ahí distribuir a todos los consumidores. Una nueva política debe propiciar la diversificación de las fuentes, logrando así mayor seguridad de suministro y menores costos e impactos por grandes transmisiones. Se necesita mejorar el marco regulatorio, que haga competitivo el mercado eléctrico, remueva 
barreras de entrada y entregue los incentivos adecuados para energías renovables con menores impactos ambientales y externalidades sociales positivas. Entre estas medidas:

- Involucrar a las comunidades locales: Desde el inicio de los proyectos se debe realizar una participación proactiva con las comunidades y actores sociales. Más que como un obstáculo para el desarrollo de proyectos, se debe ver a las comunidades locales como una oportunidad de hacer mejores proyectos y no como un estorbo para las inversiones.

- Incentivar los proyectos que generan mayor empleo: En una economía donde cada vez el empleo es más precario, se debe incorporar en la matriz de decisiones la capacidad que tienen los proyectos de energía para lograr sustentabilidad social en los territorios, mejorando el empleo de calidad.

- Diversificación de la matriz SIC y SING: El abundante recurso energético distribuido a lo largo de nuestro territorio debe ser la base para una política de diversificación, donde el Estado dé señales claras para que nuevos actores se interesen en el desarrollo de proyectos en esa línea.

- Compromiso de los sectores productivos con las ERNC: Para nadie es desconocido que la mayor demanda de energía está radicada en el sector minero, por sobre el 32\% del total, y en el sector industrial, con un 30\% de la demanda. En este escenario, es factible que los sectores productivos, especialmente el minero, hagan también su esfuerzo por incorporar al menos un 30\% de ERNC a su matriz eléctrica. Lo mismo pueden hacer otros sectores, como agricultura, por ejemplo, que tiene potenciales con centrales de paso en sus canales de regadío por sobre los 1.000 MW de potencia.

\section{REFLEXIONES FINALES}

Luego del análisis realizado, queda claro que la movilización y empoderamiento ciudadano en contra del proyecto HidroAysén y, como contrapartida, por la defensa de la Patagonia chilena, logró poner en la agenda política el tema eléctrico, a pesar de no haber estado en el programa de gobierno. El marco regulatorio eléctrico, desde el inicio de la transición a la democracia, ha tenido solo pequeñas modificaciones a través de las Leyes Cortas, marcando un antes y un después en la capacidad que tienen los temas ambientales para movilizar a la población e influir en la política pública.

Producto de la causa por la defensa de la Patagonia en mayo de 2011, la ciudadanía perdió el miedo, salió masivamente a las calles por primera vez desde el inicio de la transición a la democracia y continuó por el resto del año con las movilizaciones de los estudiantes, las minorías sexuales, los temas de salud, pueblos originarios, laborales, entre otros. 
Aún no existen las investigaciones sociológicas y los análisis que sitúen el rol que jugó el movimiento "Patagonia sin Represas" en la activación de las movilizaciones sociales y empoderamiento ciudadano que todavía remecen al país. Pero, con los antecedentes disponibles, al menos permiten formular una hipótesis, que actuó como la gota que rebalsó el vaso, luego de más de veinte años de democracia, donde una de las características de los gobiernos de la transición fue la contención del movimiento social en aras de mantener la estabilidad democrática y evitar aventuras golpistas, como las que vivió el país en su estrategia por avanzar al socialismo por la vía democrática al inicio de los años 70 .

También refleja el apoyo a "Patagonia sin Represas", y otras causas socioambientales, que en las últimas décadas la consciencia ecológica aumentó significativamente en la población chilena y ya no está reducida solo a grupos ambientalistas, sino que ha llegado a diferentes sectores sociales y estratos etarios, especialmente a los jóvenes, que ven su futuro y calidad de vida amenazados por decisiones que toman las actuales generaciones, impulsando un modelo de desarrollo que no puede ser considerado sustentable y está más bien guiado por el afán de lucro privado desmedido y la codicia por la máxima rentabilidad a corto plazo a como dé lugar.

Sin duda, este tema aún está en desarrollo y seguirá en la agenda pública, pero la influencia de las mayorías ciudadanas que apoyan a "Patagonia sin Represas" en la política ya está dando resultados, y prácticamente todos los candidatos a la presidencia que competieron el año 2013 tuvieron posiciones contrarias a HidroAysén.

Esto deja a ENDESA Chile y a su empresa propietaria, ENEL de Italia, en una difícil posición, dado que, según sus propias declaraciones, ya llevan gastados alrededor de los US\$350 millones en un proyecto que, al parecer, tendrá pocas posibilidades de concretarse.

A continuación, se presentan algunos paisajes del nacimiento del Río Pascua, desconocidos por la mayoría de los chilenos, y que serían inundados por las represas de HidroAysén:

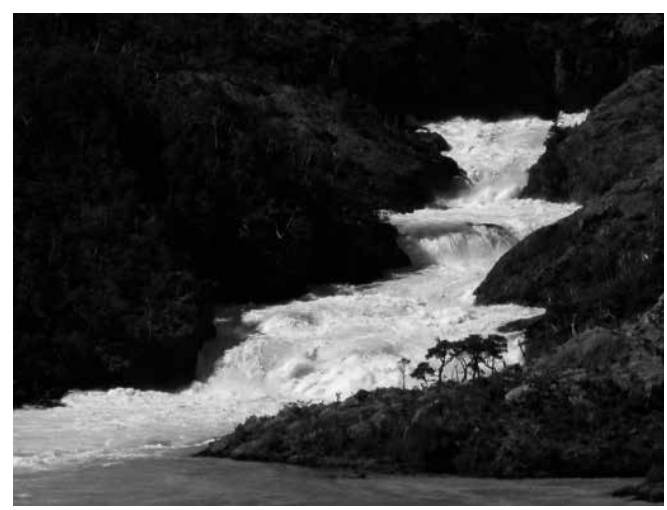

Foto 1. Saltos del Pascua

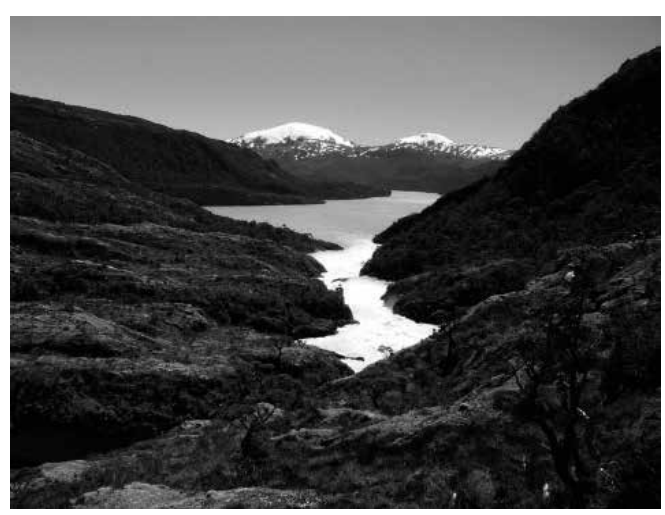

Foto 2. Saltos y Lago Chico 


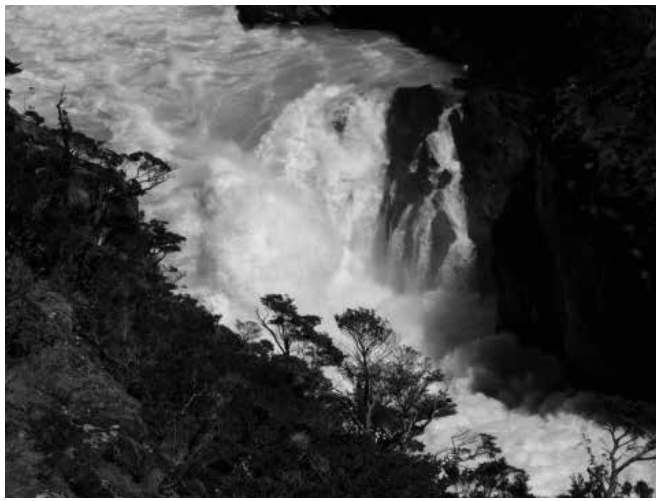

Foto 3. Cascada del Pascua

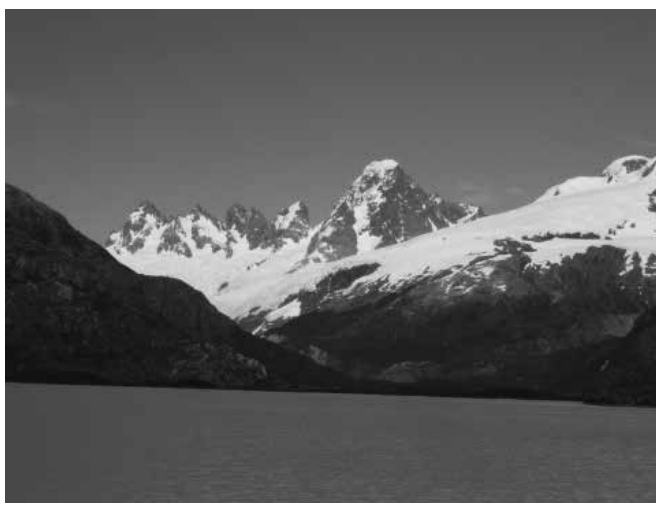

Foto 5. Montes Steffens

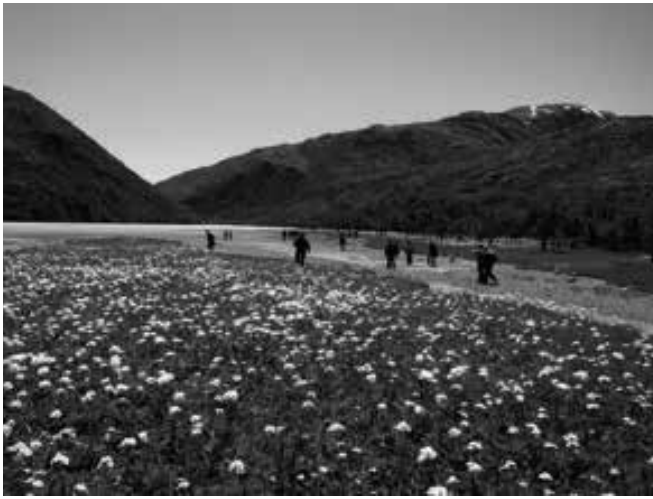

Foto 4. Nacimiento del Río

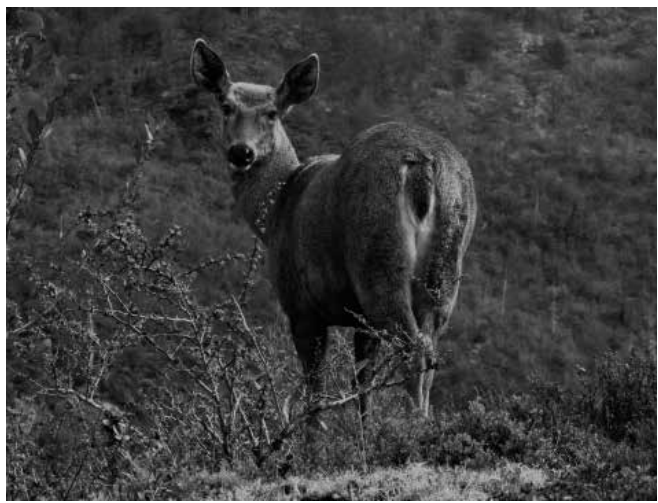

Foto 6. Huemul en el Pascua

\section{REFERENCIAS BIBLIOGRÁFICAS}

“74\% Rechaza HidroAysén”, en La Tercera, Santiago, 15 mayo 2011, sección R, pág. 10.

"Golborne presentó alcances de su plan energético a opositores a HidroAysén", en El Mercurio, Santiago, 27 mayo 2011, sección C, pág. 2.

"Nadie puede decir que esto nació por generación espontánea", en The Clinic, Santiago, 26 mayo 2011, pp. 8-9.

"El gran remezón", en La Tercera, Santiago, 22 mayo 2011, sección R, pp. 4-8.

CCTP, Chile necesita una gran reforma energética. Propuestas de la Comisión Ciudadana TécnicoParlamentaria hacia un desarrollo eléctrico limpio, seguro, sustentable y justo, Santiago, octubre 2011.

Chible, M., "El sueño de Aysén, otra visión de desarrollo", en Rodrigo, P., Orrego, J., Patagonia chilena sin represas, Santiago: Ocholibros, 2007, pp. 142-143.

Comisión Nacional de Energía, Política Energética, nuevos lineamientos. Transformando la crisis en una oportunidad, 2008. 
Consejo de Defensa de la Patagonia, Estrategia y Plan de Acción, Coyhaique, 10 octubre 2007, pp. 3-4.

Edgar, M., "Hacia una política de civilización", Rodrigo, P., Sandoval, H., Silva, C., Manifiesto de Santiago: Fin de un modelo y la emergencia de una nueva conciencia ecológica, Santiago: Editorial Ocholibros, 2009, pp. 57-65.

European Renewable Energy Council, Revolución energética. Una perspectiva energética sostenible para Chile, 2008, 55 págs.

Flanagan, C., Faison, N., "Youth civic development: Implications of research for social policy and programs", en Social Policy Report 15, 2001, (1) pp. 3 - 14.

Flanagan, C., Sherrod, L. (), "Youth political development: An introduction", en Journal of Social Issues 54, 1998, (3) pp. 447-456.

Gobierno de Chile, Estrategia Nacional de Energía 2012-2030. Energía para el futuro, 2012, 29 págs.

Hall, S., Román, R., Cuevas, F., Sánchez, P., ¿Se necesitan represas en la Patagonia?: Un análisis del futuro energético chileno. Santiago: Ocholibros, 2009, 91 págs.

Hartmann, P., "La Patagonia abusada. Cómo el territorio ha sido víctima del centralismo", en Rodrigo, P., Orrego, J., Patagonia chilena sin represas, Santiago: Ocholibros, 2007, pp. 114-115.

Krause, M., Jaramillo, A., Intervenciones psicológico-comunitarias en Santiago de Chile, Santiago: Pontificia Universidad Católica de Chile, 1998

Larraín, S., "Un plan energético para Chile. La inexistencia de una política sustentable", en Rodrigo, P., Orrego, J., Patagonia chilena sin represas, Santiago: Ocholibros, 2007, pp. 146-147.

Lecannelier, F., Conocimiento y complejidad, Santiago: LOM, 2012, 121 págs.

Lovins, A., "Reinventig Fire", en Energy, overdevelopment and the delusion endless growth, Post Carbon Institute, 2012, pp. 229-234.

Max-Neef, M., "La expropiación legal del patrimonio de los agricultores y empresarios turísticos", en Rodrigo, P., Orrego, J., Patagonia chilena sin represas, Santiago: Ocholibros, 2007, pp. 108-109.

McCully, P., "Las mega represas, inaceptables e innecesarias", Rodrigo, P., Orrego, J., Patagonia chilena sin represas, Santiago: Ocholibros, 2007, pp. 68-65.

Natural Resourse Defense Council, El costo nivelado de energía y el futuro de la energía renovable no convencional en Chile: Derribando algunos mitos, 2012, 30 págs.

Pizarro, R., "La inequidad en la distribución de la energía", en Rodrigo, P., Orrego, J., Patagonia chilena sin represas, Santiago: Ocholibros, 2007, pp. 130-131.

Puchi, V., "Producción y Cultura. Preservación de las tradiciones patagónicas", en Rodrigo, P., Orrego, J., Patagonia chilena sin represas, Santiago: Ocholibros, 2007, pp. 154-155.

Rappaport, J., "In praise of paradox: A social policy of empowerment over prevention", en American Journal of Community Psychology 9, 1981, (1) pp. 1-21.

Rodrigo, P., Orrego, J., Patagonia chilena sin represas, Santiago: Ocholibros, 2007, 180 págs.

Rodrigo, P., Sandoval, H., Silva, C., Manifiesto de Santiago: Fin de un modelo y la emergencia de una nueva conciencia ecológica, Santiago: Ocholibros, 2009, 99 págs.

Sandoval, H., "Haciendo patria, la Patagonia como patrimonio de todos los chilenos", en Rodrigo, P., Orrego, J., Patagonia chilena sin represas, Santiago: Ocholibros, 2007, pp. 170-171.

Scherr, H., El imperativo energético. Cómo hacer realidad el cambio integral hacia las energías renovables, 2011, 293 págs.

Wilson, J., "No es necesario electrocutar la Patagonia, aprendamos de la experiencia de California", en Rodrigo, P., Orrego, J., Patagonia chilena sin represas, Santiago: Ocholibros, 2007, pp. 152-153. 